\title{
Lead-Time Effect Comparison of Additive Manufacturing with Conventional Alternatives
}

\author{
Martin KURDVEa,b,1, Karl-Eric PERSSON a , Magnus WIDFELDT a , Johan \\ BERGLUND $^{\mathrm{a}, \mathrm{b}}$ and Alexander DROTT ${ }^{\mathrm{c}}$ \\ ${ }^{\text {a } R I S E-R e s e a r c h ~ I n s t i t u t e s ~ o f ~ S w e d e n, ~ G o t h e n b u r g, ~ S w e d e n ~}$ \\ ${ }^{\mathrm{b}}$ Chalmers University of Technology, Gothenburg Sweden \\ ${ }^{\mathrm{c}}$ Volvo Group, Sweden
}

\begin{abstract}
This single case study used value stream mapping as input data to analyse alternatives for production of quenching tools in an on-site tool department of an automotive manufacturer. The existing manufacturing organised as a functional workshop was compared to the alternatives, adding an additive manufacturing cell or a conventional automated cell, with regards to lead-time and needed process changes. The results indicate that lead-time savings should not be the only reason for considering additive manufacturing. When it is beneficial for design and product functionality improvements, however, lead time improvements may give a contribution to the business case.
\end{abstract}

Keywords. Additive manufacturing, Lead-time, Case study, Tool manufacturing, Scenario-based analysis method

\section{Introduction}

Although still immature in many application areas [1], additive manufacturing (AM), of steel products has developed from lab and pilot scale into being a full-scale production alternative for especially small series special part production $[2,3]$.

In automotive industry and other large volume manufacturing, a large variation of machining and quenching tools are used [4]. Tool supply to these is often done either by specialised tool suppliers or by inhouse tool manufacturing departments on-site, supporting with tools on demand. In many built-to-order manufacturing processes the lead-time is one of the most important parameters. Especially for complex and expensive replacement tools, stocks need to be kept at low levels why lead time for replenishment of tools need to be kept short.

Value stream mapping (VSM) is often used to analyse lead times and find opportunities for improvement in the value-chain [5, 6]. In addition to lead time, cost, sustainability and function of the produced tool is important when evaluating manufacturing options (e.g. AM) of such tools.

AM gives opportunity to produce customised products with advanced design ondemand, but there is a significant need for methods, frameworks and tools that will

\footnotetext{
${ }^{1}$ Corresponding Author. martin.kurdve@chalmers.se
} 
support decision makers on evaluating when and where AM is suitable in a specific case $[1,2]$. Although studies on AM technology has become more common there is need for more evaluations of what such application would give as benefit in practice $[2,3]$.

This paper elaborates in what situations AM is an alternative to conventional manufacturing of quenching tools and similar products. The research is performed as a single case study followed by an industrial workshop aiming to analyse potential lead time gains and other considerations (achieve a more flexible, agile and sustainable production) for AM. The existing tool manufacturing was compared to an AM process which was tested in pilot scale and to a hypothetical automated cell. The starting point, was to identify opportunities with AM to shorten lead times, reduce material consumption and create added value in components manufactured. The contribution pertains in an in-depth description of the decision making process involved for applying $\mathrm{AM}$ in practice.

\section{Background}

AM technology exist in a variety of process types and has been presented as more material and energy efficient processes to produce parts than conventional manufacturing $[7,8]$. In order to evaluate environmental sustainability, energy and material requirements are important to consider for the specific process. The environmental efficiency of producing a part is highly dependent on the solid-to-envelope-ratio [7]. Previous evaluations have indicated that cost of powder materials is a crucial issue for $\mathrm{AM}$, especially for high volume production, less so for low volume complex part production [3].

In order to assess the suitability of AM processing, an evaluation of the product and process needs to be performed [2]. In this, a rough economical estimation is suggested. The current conventional manufacturing and the AM alternative needs to be recorded and each manufacturing step analysed regarding process times. In addition, the product needs to be assessed regarding (re-)design for AM where basically the solid-to-envelope ratio is lowered (and as a consequence the material efficiency is improved) [7]. With facility costs being constant when comparing options of putting in a conventional or AM process, production cost for AM include capital, utilities, raw materials, labour and maintenance cost [9] which is in line with cost modelling of conventional machining [10]. Conventional manufacturing has cost and environment challenges especially regarding process fluid use, energy, tool wear, maintenance and material use [4], while emerging technologies like powder metallurgy and additive manufacturing have challenges in powder production, energy use and sometimes chemicals for post-treatment [11]. AM and dry machining share the advantage of not using cutting fluids that carries a large portion of economical and environmental burden $[4,12]$.

The largest cost parameters in conventional manufacturing lies in labour, equipment (incl maintenance) and material costs. Both material costs and equipment (aquisisition) cost is still higher for additive than for conventional manufacturing $[8,13]$, while labour need may differ mainly depending on automation level.

In summary, for many tool manufacturing settings the lead time is more crucial than the direct cost. The stand-still cost of a production line is large compared to the cost to produce one tool. Therefor it may be crucial to reduce lead time and thus risks of production stand-still by producing on demand in a tool department. One proposed way to reduce lead times have been by introducing AM [1, 7]. AM gives opportunity to 
produce customised products with advanced design on-demand, but decision makers also need to evaluate when and where AM is suitable for each case $[1,2]$.

\section{Materials and Methods}

This research was performed as a single case study with a following industrial discussion workshop, aimed to study the possibilities for introducing AM and shorten lead-times. The project AMtoFlex has researched the possibilities to achieve a more flexible and agile production by introducing AM and shorten lead-times in different production chains generally portraied in Figure 1.

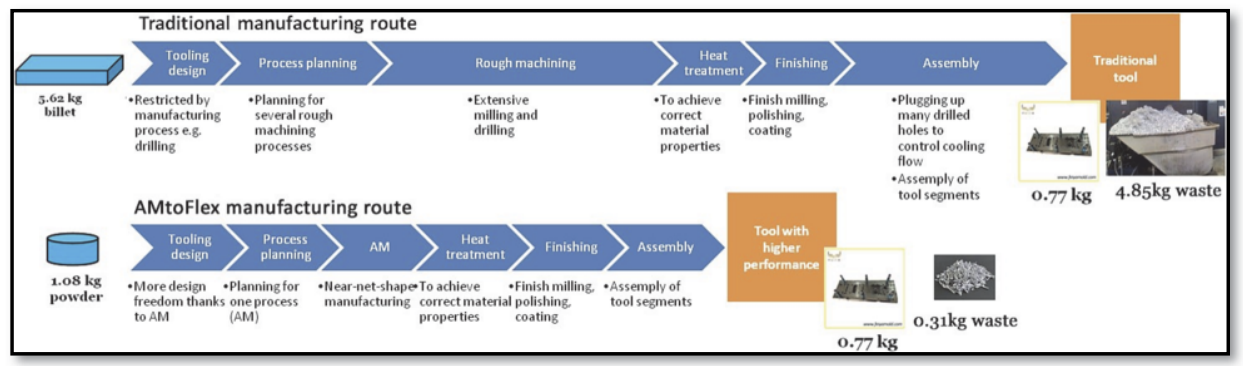

Figure 1. The project aim to shorten lead-time, increase material efficiency and increase flexibility.

The case study was done in an on-site tool department of an automotive manufacturer in Sweden. The tool department is organised as a functional workshop with parallel cells and queuing jobs for each cell. It operated daytime shift and has several operations e.g. turning, milling, drilling, grinding.

The quenching tools used by the automotive manufacturer consist of a mandrel and press-rings, see figures 2 and 3. The produced heated part is thread onto the mandrel, fixated by the press-rings and cooled in the quenching operation. After cooling, the part is pressed off the mandrel. The mandrel is subject to large pressure and torque forces in the production operation where it is used. The tools come in different sizes.

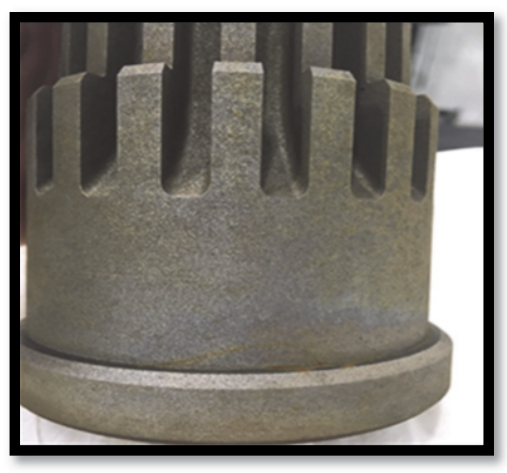

Figure 2. Photo of mandrel detail.

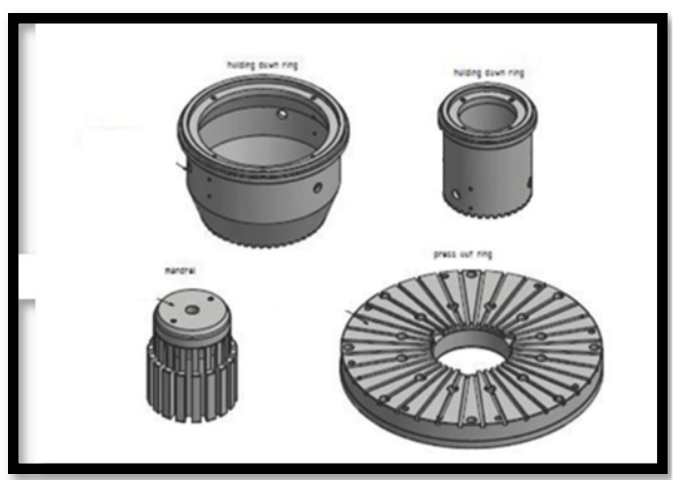

Figure 3. Drawing of mandrel and other tool parts. 
In order to evaluate suitability of AM, an assessment of the product and process was performed $[1,2]$ to compare the current mode of operation, procurement via purchase from a supplier, and the consequences of replacing the current situation with two AM alternatives. A comparison of different ways of producing the mandrel based on processes, lead times, flexibility and tool development potential was made for four scenarios:

1. Manufacturing in existing tool shop: (Current-state)

2. Manufacturing in a new multi-operation machine with robot operation: (Multi$\mathrm{OP})$

3. Manufacture in metal printers and finishing: (Initial-AM)

4. Possible additional effects of initial redesign for AM: (Improved-AM)

Value stream mapping was used to collect input data onsite and to do lead-time analysis of manufacturing of one quenching tool [5]. The existing conventional production of tools in the tool shop was analysed on site, operation times were estimated from similar operations/tools. Queue-time was estimated from the existing queue at each operation. The lead time was calculated in manned hours. This means that all times can be translated to working days by dividing number of hours with 8 or (ordinary day time) working weeks by dividing with 40 .

All assumptions for Multi-Op scenario was based on the Current-state where rough machining operations (turning, milling, drilling,) were made in an automated multioperation machining operating as specified by the potential supplier on unmanned-shifts as well as manned.

Assumptions for the Initial-AM scenario, where all operations until finishing operations are replaced in the 3D-printing value chain, were based on 3D printing at RISE IVF, surface/heat treatment and finishing in the studied tool department. Data for AM operations were collected at the RISE IVF lab where the investigated tool was manufactured in a pilot trial. The process and set-up times were based on the time from producing only two tools in a full-scale 3D-printer. However, process times were mainly dependent on amount of material thus the order of size is expected to remain also when operating in full scale unless design optimisation as in Improved-AM scenario is performed.

An assumption for the Improved-AM scenario is that the reduction of 3D-printing process time is equal to the reduction of $3 \mathrm{D}$-printing powder $(\%)$. The potential reduction of powder was estimated based on interviews with the designer of the quenching tool and on literature [14].

In the analysis, a comparison with regards to lead-time and needed process changes were performed. Workshop discussion with expert practitioners were used to extract opportunity ideas for future improvements that may affect the decision to introduce AM in the setting.

\section{Results}

The use of scenarios and value stream mapping as methods for production development pre-studies including AM, is presented and discussed.

The Current-state tool production system was mapped in Figure 4. The critical bottleneck operations in the value stream for the tool is in the milling operations. In scenario Multi- 
OP a new hypothetical conventional multioperation machine replaces turning, milling and drilling. The operation data for the machine was estimated based on data in offerings from machine supplier. The third scenario, to exchange cutting, turning, milling, drilling and heat treatment with AM followed by electro discharge machining and annealing used real data from the 3D printer at RISE. Finally, the fourth scenario estimated operation times based on optimized design of the tool.

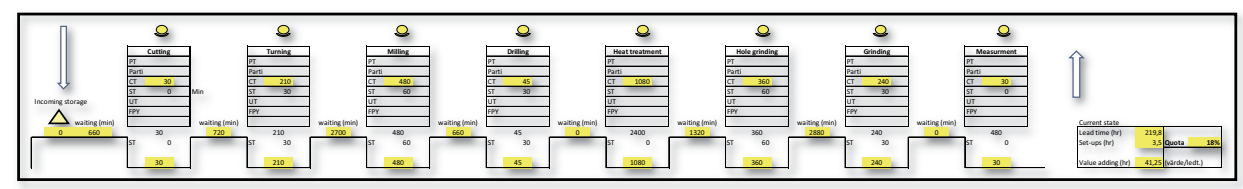

Figure 4. Value stream map of Current-State process.

Analysis of the Current-state gave a lead time of 220 hours (271/2 working days) with value adding/process time 41 hours and the sum of setup-times ca 3.5 hours. Analysis of the automated Multi-OP scenario gave a lead-time of 144 hours (18 working days) with value adding time 41 hours and sum of setup times 3.5 hours. The Initial-AM scenario gave 204 hours (251/2 working days) lead time with 152 hours value adding/process time and sum of setup-times ca 2 hours.

In the Multi-OP scenario a new machining operation replaces the bottleneck operations (figure 5) and in the Initial-AM all initial operations are replaced (figure 6) The lead-time gains in both the automated Multi-OP and in Initial-AM scenarios comes from two types, a) being able to reduce number of operations and thus number of queues in the process and b) enabling unmanned operation and thus reducing lead time calculated in manned hours.

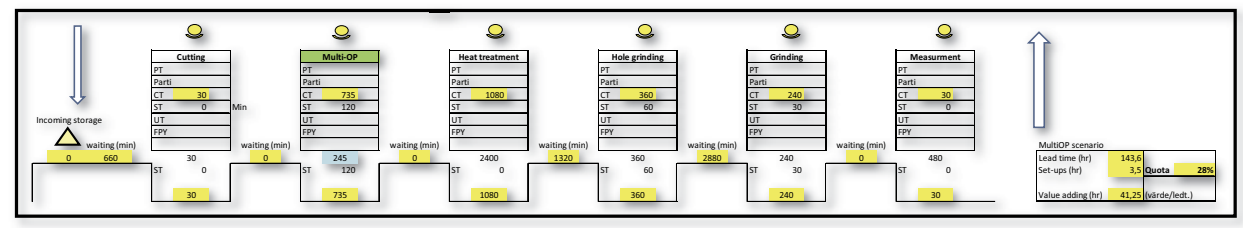

Figure 5. Value stream map of the Multi-OP scenario.

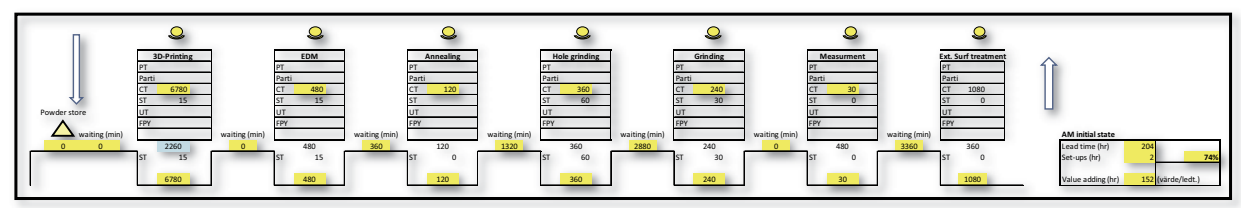

Figure 6. Value stream map of the Initial-AM scenario.

In the Initial-AM scenario, the quenching tool was not optimized for AM in neither tool design or in set-up into the AM-machine. After analyzing the flow an Improved-AM 
(Figure 7) was estimated based on reducing 67\% filling material in the tool design and the final surface treatment could be ommitted by choosing another powder material. The new design is thus hollow to some degree, and the estimation gave a resulting total lead time reduction by half, down to to 116 hours, (14,5 working days) the same set-up time 2 hours and total value adding time 58 hours. The lead time reduction lies in printing time and ommitting final surface treatment.

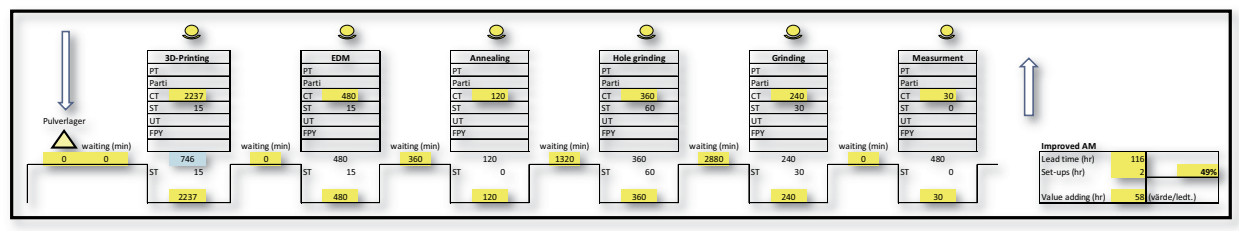

Figure 7. Value stream map of the Improved-AM scenario.

\section{Analysis and discussion}

The Initial-AM gives longer lead time than the Multi-OP. However, AM should never be applied without redesigning at least the part itself [14], thus, if the tool is redesigned and optimized for AM there exist a potential to reduce total lead time even more in the Improved-AM scenario. The resulting lead times and value adding time as shown in figure 7 are lower than the conventional Multi-OP scenario. The large leadtime reduction compared to the Current-state is connected to the fact that the tool department is only manned on day shift. Thus by thorough planning AM is a viable option in spite of long procssing times.

The major costs in manufacturing are materials, personnel and equipment [13]. Table 1 shows how these cost aspects are higher or lower compared to the Current-state scenario. Operator time is reduced in all scenarios while equipment cost are increased, these two cost aspects can perhaps be balanced. Regarding the material cost, even if the material weight is reduced to one third in Improved-AM compared to Initial-AM and Multi-OP the price of the powder is more than three times as expensive as the conventional material. Thus from an immediate cost perspective it may be a good idea to be catious with regards to investing in AM and make sure that there are other benefits involved.

Table 1. An overview of the results from the three scenarios, compared to the current state manufacturing.

\begin{tabular}{ccccc}
\hline Scenario/Cost & Materials cost & Equipment cost & Labour cost & Lead time \\
\hline Multi-OP & Same & Higher & Lower & Lower (2/3) \\
Initial $-A M$ & Higher & Higher*3 & Lower & Same \\
Improved- $A M$ & Higher/3 & Higher*3 & Lower & Lower $(1 / 2)$ \\
\hline
\end{tabular}

For the environmental and occupational hazards considerations there are often general benefits in reduction of environmental impact and heath risks when upgrading to newer equipment, but the environmental impact from producing the equipment needs to be taken into account as well. AM has benefits of using less materials, chemicals and energy $[7,8]$ but there are other issues regarding the metal powder bringing both new occupational hazards and environmental impacts. So "it depends" (Diegel et al. [14] p.142). However in the applied case, as one operation among others in the tool- 
manufacturing department of a large automotive production site, the personnell are used to handle various hazardous materials and thus metal powder would not increase occupational hazards, it would rathher reduce risks since less operations in old open machines emmiting cutting fluids will be used. For environmental (and cost) concerns it is important which source of metalpowder is used [3,7]. There is need for more research on how to reap environmental benefits from AM without adding new risks or hazards,regarding powder especially.

When redesigning for AM there may be possibilities of adding value or function to the tool, so that it works better than the conventional tool. Thus, it is easy to add cooling channels or other performance enhancing options to the tool during redesign. In that case maybe both tool change frequency and cycle time for the operation where the tool is used can be improved. Such improvements may recover both increase of cost and improve environmental impact by lowering cost and environmental impact in the use-phase. In addition there may be both organisational learning challenges and benefits involved in introducing AM in the workshop. By allowing experimentation a better knowledge of critical part designs can be reached and thus future process improvements. It may also be crucial to be ready and have experience of the AM technology in advance. Problem based learning with experiments and connection to researchers may be as important as investment in the actual equipment [14].

\section{Conclusion}

The case study results indicate that lead-time savings should not be the only reason for considering AM. When AM can be done with beneficial redesign and product functionality improvements, however, lead time improvements may give contribution to the business case. The case contributes by demonstrating a scenario-based analysis approach to use in research case studies and industrial decision making.

\section{Acknowledgement}

This research was performed within the project AMtoFlex, financed by Produktion2030, a strategic innovation programme supported by Vinnova, the Swedish Energy Agency and Formas and within Chalmers Area of Advance Production.

\section{References}

[1] Bikas, H., S. Koutsoukos, and P. Stavropoulos, A decision support method for evaluation and process selection of Additive Manufacturing. Procedia CIRP, 2019. 81: p. 1107-1112.

[2] Ilg, J., A. Oehler, and D. Lucke, A Suitability Analysis Method for Additive Manufacturing Technologies in Small and Medium-Sized Companies. Procedia CIRP, 2019. 81: p. 612-617.

[3] Simons, M., Additive manufacturing - a revolution in progress? Insights from a multiple case study. The International Journal of Advanced Manufacturing Technology, 2018. 96(1-4): p. 735-749.

[4] Gupta, K., et al., Recent developments in sustainable manufacturing of gears: a review. Journal of Cleaner Production, 2016. 112: p. 3320-3330.

[5] Rother, M. and J. Shook, Learning to see: value stream mapping to create value and eliminate muda. 2003, Cambridge, MA: Lean enterprice instituteincorporated. 
[6] Dal Forno, A.J., et al., Value Stream Mapping: a study about the problems and challenges found in the literature from the past 15 years about application of Lean tools. The International Journal of Advanced Manufacturing Technology, 2014. 72(5-8): p. 779-790.

[7] Watson, J. and K. Taminger, A decision-support model for selecting additive manufacturing versus subtractive manufacturing based on energy consumption. Journal of Cleaner Production, 2018. 176: p. 1316-1322.

[8] Diegel, O., et al., Additive manufacturing and its effect on sustainable design, in Handbook of sustainability in additive manufacturing. 2016, Springer. p. 73-99.

[9] Panicker, S., et al., Tracing the Interrelationship between Key Performance Indicators and Production Cost using Bayesian Networks. Procedia CIRP, 2019. 81: p. 500-505.

[10] Bengtsson, M. and M. Kurdve, Machining Equipment Life Cycle Costing Model with Dynamic Maintenance Cost. Procedia CIRP, 2016. 48: p. 102-107.

[11] Kianian, B. and C. Andersson. Sustainability-Conscious Powder Metallurgy Gear Manufacturing: an analysis of current manufacturing challenges. in International Conference on Gear Production 2017. 2017. VDI-Verlag GmBH.

[12] Kurdve, M. and L. Daghini, Sustainable metal working fluid systems: Best and common practices for metal working fluid maintenance and system design in Swedish industry. International Journal of Sustainable Manufacturing, 2012. 2(4): p. 276-292.

[13] Kianian, B., M. Kurdve, and C. Andersson, Comparing Life Cycle Costing and Performance Part Costing in Assessing Acquisition and Operational Cost of New Manufacturing Technologies. Procedia CIRP, 2019. 80: p. 428-433.

[14] Diegel, O., A. Nordin, and D. Motte, Teaching Design for Additive Manufacturing Through ProblemBased Learning, in Additive Manufacturing-Developments in Training and Education. 2019, Springer. p. 139-149. 